\title{
Presencia de Eunomio de Cízico en los tres primeros libros del De Trinitate de Hilario de Poitiers
}

\author{
José Luis Narvaja \\ FACULTADES DE FILOSOFÍA Y TEOLOGÍA DE SAN MIGUEL (ARGENTINA) \\ jlnarvaja@gmail.com
}

Resumen: Los estudiosos están de acuerdo en la complejidad de la estructura y la cronología de los 12 libros del De Trinitate de Hilario de Poitiers. Sin embargo, no coinciden en el momento de darle un orden y de datarlos individualmente. La consideración de la teología neoarriana tal como se desarrolló durante el período en que Hilario vivió su exilio en el oriente, ofrece un nuevo elemento que puede ayudar a considerar los tres primeros libros como los que fueron escritos en último lugar, después del 360, cuando Hilario regresa a la Galia.

Palabras clave: Hilario de Poitiers - De Trinitate - Eunomio de Cízico - Apología - arrianismo.

Abstract: On the stucture and chronolgy of Hilary of Poitiers' 12 books on De Trinitate, there is a general agreement among scholars, but not on their exact sucession and specific chronology of each book. A look on neoarrian theology as developed during Hilary's exile sugests that the first three books were the last to be written, after 360, when their author was back in Gaul.

Keywords: Hilary of Poitiers - De Trinitae - Eunomius of Cizico - Apology arrianism 
1. Introducción: Problema de la cronología y estructura del De TRINITATE

En un artículo sobre la estructura y la cronología del De Trinitate de Hilario de Poitiers, Manlio Simonetti analiza y excluye la tesis de Paul Galtier ${ }^{1}$ acerca de la fecha de composición de los tres primeros libros de dicha obra. Según Galtier estos libros pudieron haber sido escritos antes del exilio de Hilario en el $356^{2}$.

Es comúnmente aceptado que estos tres libros formaban un escrito separado, fusionado luego con el resto de la obra en un momento -según Simonetti- «no identificable», pero que debieron haber sido escritos al principio del exilio, entre el fin del 356 y principios del $357^{3}$.

Por otra parte, refiriéndose a las doctrinas heterodoxas que combate Hilario, Simonetti encuentra referencias al arrianismo de Eudoxio y de Aecio en la analogía entre la generación divina y la generación carnal ${ }^{4}$. No menciona ningún otro autor arriano que pudiera estar en el trasfondo del pensamiento del obispo de Poitiers.

Es mi intención en estas páginas estudiar la relación que encuentro entre los tres primeros libros del De Trinitate de Hilario y la teología del arrianismo de la segunda generación como la vemos testimoniada en la obra de Eunomio de Cízico5.

Sabemos que Hilario, después de haber participado del concilio de Seleucia (comenzado el 27 septiembre de 359), se dirigió a Constantinopla junto con la delegación que debía presentar al emperador los resultados de dicho concilio. Debido a las presiones del emperador y a las resistencias de la delegación, los representantes del concilio permanecieron en la ciudad imperial hasta el 31 de diciembre de 359 en que se plegaron a la voluntad imperial y firmaron la fórmula de fe homea ${ }^{6}$.

1 Cf. P. Galtier, Saint Hilaire de Poitiers, le premier docteur de l'Église latine (París 1960), 35ss.

2 Cf. M. Simonetti, "Note sulla struttura e la cronologia del De Trinitate di Ilario di Poitiers", Studi Urbinati 39 (1965), 273-300, me refiero aquí a p. 275.

Cf. M. SimonetTi, "Note sulla struttura ...", 300.

Cf. M. SimonetTI, "Note sulla struttura... “, 281-282.

5 Estudiaremos la Apologia de Eunomio, del año 357. Véase Eunomio de Cízico, Obra teológica, Buenos Aires 2015, 7-35.

6 Cf. M. Simonetti, La crisi ariana nel IV secolo, Augustinianum, Roma 1975, 326327 y C. Bordchardt, Hilary of Poitier's role in the Arian struggle, The Hage 1966, 166-167. 
Por otra parte, sabemos que en diciembre del año 359 Aecio «secundado por Eunomio» su discípulo y secretario, intervino en un sínodo en Constantinopla ${ }^{7}$ Gregorio de Nisa nos da testimonio de que este sínodo fue la ocasión en la que Eunomio pronunció su Apología. Allí estaba presente también Basilio de Cesarea, aún diácono ${ }^{8}$.

Aunque no tenemos ninguna noticia al respecto, no parecería extraño que Hilario hubiera estado presente en el sínodo. Pero lo que podemos considerar cierto es que tuviera conocimiento de la doctrina neoarriana tal como nos queda testimoniada en la Apología que Eunomio presentó en dicho sínodo.

Si leemos los tres primeros libros del De Trinitate desde esta perspectiva, encontramos muchas similitudes con la obra de Eunomio, aunque no hay citas textuales de la misma.

\section{El debate de los tres primeros libros del De trinitate}

En el primer libro del De Trinitate, después de una presentación autobiográfica (I 1-17), expone Hilario unas instrucciones para quienes leen el libro (I 18-19). Estas instrucciones enmarcan el problema que tiene en mente Hilario al escribir estos tres libros. Por un lado debemos decir que se corresponden en la temática a la peroración final del libro III mostrando la unidad de esta obra en tres libros. Por otra parte, nos permite dar una respuesta al problema que la crítica se ha puesto acerca del valor del relato autobiográfico.

Las notas explicativas en los capítulos 18 y 19 del libro tratan acerca del problema del conocimiento de la verdad. El número 18 comienza con una critica a quienes consideran que se puede llegar al conocimiento de Dios por medio de la sola razón. Dice:

Vosotros, a quienes impulsó a leer el fervor de la fe y el afán por la verdad, ignorada por el mundo y por los sabios del mundo, es necesario que recordéis que las opiniones sin peso ni consistencia de las mentes terrenas han de ser rechazadas y que todas las estrecheces del

\footnotetext{
Cf. Filostorgio, Historia Ecclesiastica, IV 12.

8 Cf. Gregorio de Nisa, Contra Eunomium, I 78-79.
} 
pensamiento imperfecto han de ser abiertas por el deseo creyente de aprender?.

Se trata de un conocimiento "terreno", "sin consistencia" e "imperfecto". Es el conocimiento que se funda solamente en la razón humana. A este tipo de pensar, contrapone Hilario el de los que tienen fe, quienes deben buscar nuevos caminos de razonamiento. Continúa diciendo:

Los espíritus regenerados necesitan nuevos modos de razonar para que cada uno sea iluminado por su conciencia según el don que viene del cielo ${ }^{10}$.

El conocimiento de Dios, en primer lugar, no es un don natural, sino que es un don que viene de Dios mismo. Desde este punto de partida de la fe, el creyente puede luego, gracias a su inteligencia-que también es don de Dios-, profundizar esas verdades reveladas. Prosigue Hilario:

Ante todo se deben tener ideas firmes, gracias a la fe, sobre la sustancia divina para que quien va a oír hablar acerca de la sustancia de Dios dirija su pensamiento hacia aquello que es digno de la sustancia divina y no se deje guiar por ningún otro modo de pensar, sino por su infinitud ${ }^{11}$.

El punto "firme" que conforma la norma para la interpretación teológica es la fe. No se debe juzgar la verdad revelada desde la razón, sino la razón desde las verdades de la fe. Describe, luego, esa nueva forma de razonar en un método analógico, pero puntualizando que el analogado principal no es la criatura, sino Dios:

El que es consciente de que ha sido hecho partícipe de la naturaleza divina [...] no ha de medir la naturaleza de Dios por las leyes de su propia naturaleza, sino que ha de apreciar las manifestaciones divi-

9 "Et vos quidem, quos fides calor et ignoratae mundo ac sapientibus mundi veritatis studium ad legendum vocavit, meminisse oportet terrenarum mentium infirmas atque imbecillas opiniones esse abiiciendas, et omnes imperfectae sententiae angustias religiosa discendi exspectatione laxandas.", Hilario De Trinitate I 18 (la traducción castellana es de L. Ladaria, en Hilario de Poitiers, La Trinidad, BAC, Madrid 1986, 48-49.

10 "Novis enim regenerati ingenii sensibus opus est, ut unumquemque conscientia sua secundum coelestis originis munus illuminet." Hilario, De Trinitate, I 18, 49.

11 "Standum itaque per fidem ante est [...] in substantia Dei: ut de substantia Dei auditurus, sensum suum ad ea quae Dei substantiae sint digna moderetur; moderetur autem non aliquo modo intelligendi, sed infinitate." Hilario De Trinitate, I 18, 49. 
nas según la excelencia del testimonio que Dios ha dado acerca de sí mismo ${ }^{12}$.

Pero da un paso más, afirmando que el asentimiento de la fe no debe manipular ni forzar el dato revelado en un intento por acomodar las palabras de la Escritura a los conceptos concebidos previamente por el propio razonamiento:

El mejor lector es aquel que espera recibir de las palabras mismas el sentido de lo que se dice más que imponérselo, que retiene más que añade y no obliga a que parezca que está en los textos lo que él antes de su lectura presumía que había de entender ${ }^{13}$.

Siguiendo la tradición origeniana, subraya Hilario que la interpretación de la Escritura, su sentido auténtico, está incluido en la Escritura misma y no es necesario buscar claves de interpretación fuera de ella. El número siguiente (I 19) describe más detalladamente los dos primeros momentos de la analogía: un momento afirmativo y otro negativo. El momento afirmativo surge de la certeza de que a partir de la criatura la mente humana puede vislumbrar "algo" del Creador.

Si nosotros, al hablar de la naturaleza de Dios y de su nacimiento, aducimos a modo de ejemplo algunas comparaciones $[\ldots]^{14}$.

Pero estas comparaciones no son perfectas, por eso se necesita el momento negativo del razonamiento.

No hay comparación posible de las cosas terrenas con Dios, pero la debilidad de nuestra inteligencia obliga a buscar algunas imágenes de las cosas inferiores que puedan servirnos de indicio de lo que son las cosas superiores, de modo que con el estímulo de las cosas que por costumbre nos son familiares podamos ser llevados, a partir de

12 "Quin etiam conscius sibi divinae se naturae participem [...] effectum fuisse, Dei naturam non naturae suae ligibus metiatur, sed divinas professiones secundum magnificentiam divinae de seprotestationes expendat." Hilario, De Trinitate, I 18, 49.

13 "Optimus enim lector est, qui doctorum intelligentiam exspectet ex dictis potius qum imponat et retulerit magis quam attulerit, neque cogat id videri dictis contineri, quod ante lectionem praesumpserit intelligendum.» HiLARIo, De Trinitate, I 18, 49.

14 «Si qua vero nos de natura Dei et nativitate tractantes, comparationum exempla afferemus [...].» Hilario, De Trinitate, I 19, 50. 
la experiencia de nuestro pensamiento, a la idea de aquello que no acostumbramos a experimentar ${ }^{15}$.

Por tanto, el lector comienza la lectura del De Trinitate con una clara descripción del problema del conocimiento de Dios y del método para profundizar este conocimiento.

En la peroración final de estos tres libros (III 24-26) Hilario retoma el tema del conocimiento y la insuficiencia de la mente humana para penetrar los misterios divinos, en una neta correspondencia con las notas explicativas del libro I, de manera que, como señala Simonetti, pareciera ser la conclusión no de un libro, sino de una entera obra ${ }^{16}$.

Comienza exhortando al lector a evitar la vanagloria que lo puede llevar a creerse conocedor avezado de la infinitud de Dios.

No se debe confiar tanto en la inteligencia humana que uno llegue a creer que conoce perfectamente aquello que sabe [...]. Pues lo imperfecto no puede concebir lo perfecto [...] aquel que no puede sobrepasar las fronteras de su naturaleza y cree que todas las cosas se contienen en el ámbito de su limitación se gloría en falso con el nombre de la sabiduría pues no le está permitido saber más allá de su inteligencia y es tan débil en el entendimiento como lo es en su capacidad de subsistir ${ }^{17}$.

Quien no tiene un conocimiento realista de lo que es el hombre y de la debilidad de la mente humana será arrastrado por su soberbia a establecerse como juez de la veracidad de los misterios divinos:

La causa de la increencia [es decir de la herejía arriana] está en la flaqueza del pensamiento, por el que uno piensa que no ha podido

15 «Comparatio enim terrenorum ad Deum nulla est: sed infirmitas nostrae intelligentiae cogit species quasdam ex inferioribus, tamquam superiorum indices quaerere; ut rerum familiarium consuetudine admonente, ex sensus nostris conscientia ad insoliti sensus opinionem educemur.» Hilario, De Trinitate, I 19, 50.

16 Cf. M. Simonetti, “Note sulla struttura ...”, 178.

17 "Non est autem in tantum confidendum prudentia humana, ut perfectum se quis putet sapere quod sapiat [...]. Non enim concipiunt imperfecta perfectum [...] quia naturae suae non moderans necessitatem, et omnia infirmitatum suarum existimans terminis contineri, falso iam sapientiae nomine gloriatur: quia sapere, sibi ultra sensus sui non liceat potestatem, et quam infirmum subsistendi est virtute, tam sensus sit." Hilario, De Trinitate, III 24, 135. 
acontecer aquello que define como irrealizable [de la generación del Hijo $]^{18}$.

Porque el colmo de la debilidad de la mente humana no está en ser incapaz de conocer plenamente el misterio, sino en desconocer sus propios límites.

Distingue, luego, dos formas de acercarse a Dios: por un lado quienes tienen fe y confían en quien es fundamento de esa fe; por otro, aquellos que confían en su propia capacidad y niegan todo aquello para lo cual no hallan una explicación racional.

[...] a los que creen se les otorga la salvación mediante lo que la opinión humana cree necedad; así los increyentes juzgan insensato todo lo que va más allá de su inteligencia y los fieles confían en la potencia y la fuera de Dios que les dará todos los misterios de la salvación ${ }^{19}$.

De esta manera, llega Hilario a la última consecuencia de un pensamiento que se basa en la fe: aceptar lo que Dios nos ha revelado acerca de sí mismo y no poner coto a su acción salvadora.

Nada de lo que se refiere a la acción de Dios ha de ser tratado según el parecer de la inteligencia humana, ni la criatura, que es fruto de su obrar, ha de juzgar acerca de su Creador. [...] Cuando, una vez reconocida la insensatez de nuestra inteligencia, seamos conscientes de la ignorancia y la imprudencia propias de nuestra sabiduría [...], entonces no pondremos límites a la fuerza y al poder de Dios, no encerraremos al Señor de la naturaleza dentro de las leyes naturales, comprenderemos que solo esto debemos creer acerca de Dios: aquello que él mismo nos ha atestiguado y enseñado que tenemos que creer $^{20}$.

18 "Causa enim infidelitatis de sententia est infirmitatis, dum gestum esse quia non putat, quod geri non posse definiat.” Hilario, De Trinitate, III 24, 136.

19 "[...] per opinionem stultitiae humanae credentibus salus tribuitur: dum et infideles, quae extra sensum suum sunt, stulta esse decernunt, et fideles potestati ac virtuti Dei omnia largiendae sibi salutis suae sacramenta permittunt.” Hilario, De Trinitate, III 25, 137.

20 "Nihil igitur in divinis effectibus humanae mentis opinione tractandum est, neque de creatore suo opificii ipsius materia decernat. [...] Cum enim recognita stultitiae nostrae intelligentia, imperitiam naturalis in nobis imprudentiae senserimus, tum [...] sine modo virtutes Dei ac potestatem metiamur, cum naturae Dominum non intra naturales leges cohibeamus, cum hoc solum de Deo bene credi intelligamus, ad quod de se credendum ipse sibi nobiscum et testis et auctor exsistat." Hilario, De Trinitate, III 26, 138-139. 


\section{LA FILOSOFÍA DE EUNOMIO}

El contundente ataque de Hilario a una teología racionalista y la consiguiente defensa de un pensamiento que sea respetuoso de la palabra revelada en la Escritura y que reconozca humildemente la debilidad de la mente humana ante la infinitud de Dios y de sus misterios, nos lleva a buscar cuál es la doctrina a la que apunta la invectiva del obispo de Poitiers.

Pareciera claro que Hilario tiene en mente la enseñanza de la segunda generación del arrianismo en su grupo radical dirigido por Aecio y Eunomio. Se trata de una teología de matriz platónica, pero que formalmente se sirve de la lógica aristotélica.

El único testimonio de esta teología que ha llegado hasta nosotros es la obra de Eunomio, quien, de hecho, en la Apología afirma:

Hemos confesado un solo Dios, conforme, a la vez, al conocimiento natural y a la enseñanza de los Padres $^{21}$.

Porque Eunomio pone al mismo nivel el conocimiento natural y el conocimiento de la fe. De esta manera niega la necesidad de una mediación, pues la estructura natural del hombre le permite llegar a un conocimiento perfecto de Dios $^{22}$.

La teología neoarriana -como vemos en la Apología-, se funda en una teoría del conocimiento y en una filosofía del lenguaje desarrollada a partir del Cratilo y de los Oráculos caldeos, amalgamada con el relato bíblico de la creación.

No puedo profundizar en este momento la teología de Eunomio. Sin embargo, voy a presentar muy brevemente los puntos fundamentales de esta doctrina ${ }^{23}$.

21 Eunomio, Apología, 7, 16.

22 Cf. J. L. Narvaja, "Algunas notas sobre la doctrina antropológica de Hilario de Poitiers: conocimiento natural y conocimiento de la fe", Cadernos Patrísticos 6 (2008), 183-205, me refiero aquí a 195-196.

23 He dedicado una monografía a la teología eunomiana, cf. J. L. NARVAjA, Teología y Piedad en la obra de Eunomio de Cízico, Roma 2003. Pueden verse otras publicaciones mías sobre la teología eunomiana: J. L. Narvaja, "Tradición y Escritura en la teología de Eunomio de Cízico”, Stromata 59 (2003), 161-197 y J. L. Narvaja, "Aspectos antropológicos de la teología de Eunomio de Cízico", Cadernos Patrísticos 6 (2008), 151-171. 
Para Eunomio, los nombres tienen un valor sagrado y expresan la esencia de las cosas, pues son los nombres que Dios ha entregado al Demiurgo (el Hijo) para que realizara la obra de la creación. Estos nombres han sido grabados en el alma del hombre en el momento en que ha sido creado (son innatos y connaturales), como se puede ver por el hecho de que Dios llamó a Adán para que pusiera nombre a las bestias, al mismo tiempo que Dios asentía con los nombres que Adán les daba.

Lógicamente, concluye esta teoría del conocimiento afirmando que al conocer los nombres de las personas divinas -que para Eunomio son «inengendrado» (el Padre) y «engendrado» (el Hijo)- se obtiene un conocimiento perfecto de la esencia de Dios.

De hecho, según un testimonio de Sócrates Escolástico, Eunomio afirmaba que quien conoce el nombre de Dios, conoce a Dios tal y como él se conoce a sí mismo ${ }^{24}$.

La consecuencia última de esto es que, si los nombres «inengendrado" y "engendrado", expresan la esencia del Padre y del Hijo, debemos reconocer su diferencia esencial. De aquí que fueran llamados anomeos.

Esta forma de gnosticismo racionalista debió haber encontrado gran apoyo en quienes buscaban una teología científica y debió suscitar una profunda preocupación de parte de la gran Iglesia que veía la solidez intelectual de un razonamiento erróneo. Lo podemos intuir a partir de la cantidad de autores que la han combatido. No deja Hilario de participar de esta preocupación que hemos encontrado en el centro de estos tres libros.

Quisiera abordar, a continuación, dos puntos que ilustren más concretamente la presencia de la teología neoarriana en el De Trinitate: (1) La presentación autobiográfica en el libro I; y (2) el punto de partida de la reflexión trinitaria en el libro II.

\section{Presentación autobiográfica (De Trinitate I 1-17)}

El itinerario descrito en De Trinitate I 1-17 por medio del cual Hilario alcanza al conocimiento de Dios, también ha merecido atención de

24 Cf. Eunomio de Cízico, Obra teológica, 124. 
la crítica, que ha encontrado dificultad en calibrar el valor histórico del relato autobiográfico ${ }^{25}$.

La descripción de este itinerario tiene una intención teológica y polémica y está en perfecta consonancia con la polémica que hemos encontrado en el cuerpo de la obra.

Su búsqueda de Dios comienza con la filosofía y con el conocimiento natural, pero en un determinado momento necesita dar un salto para abrazar el conocimiento de la fe que lo lleva a un conocimiento más acabado.

De ninguna manera se trata de un doble camino paralelo, al estilo del doble método que describe Eunomio en el capítulo 20 de la Apología:

Hay dos caminos marcados para el descubrimiento de lo que buscamos: uno es aquel por el cual examinamos las sustancias mismas [...]; el otro es una investigación a partir de las actividades ${ }^{26}$.

Por el contrario, para Hilario el momento del conocimiento de la fe supera y perfecciona al del conocimiento racional.

El primer momento solo se sirve de la razón. Hilario lo recorre hasta las últimas consecuencias. La razón le permitirá conocer la vocación eterna del alma y la existencia de Dios, y le sirve asimismo para negar de Dios lo que es indigno de él y afirmar lo que se puede decir de Él convenientemente.

25 Cf. J. L. Narvaja, "Algunas notas sobre la doctrina ...”, 193. C. Kannengiesser, "Hilaire de Poitiers (saint)", Dictionaire de Spiritualité, ascétique et mistique, VII (1969), 466-499, me refiero aquí a 466-467, dice que el problema requiere un estudio detallado que permita saber si se trata de una auténtica autobiografía o de un itinerario ideal del alma. M. Simonetti "Hilario de Poitiers" en Diccionario Patrístico y de la Antigüedad Cristiana I (1991), 1033-1036, aquí 1033, opina que no tiene ningún valor histórico. M. CANÉVET, «Le schema de conversion dans le prologue du De Trinitate d'Hilaire de Poitiers et le livre VII des Confessions d'Augustin: problématique d'un temps», Augustininanum 27 (1987), 165-174, encuentra un esquema común con otros autores, como si se tratara de un tópico. M. Dormagen, Saint Hilaire de Poitiers et l'arianisme (Saint-Cloud 1864), aquí 68, puso este relato en el contexto de la controversia arriana, aunque afirma que no tiene un contexto polémico. Ningún estudioso ha seguido esta pista.

26 Eunomio, Apología, 20, 26. 
De esta manera afirma tres conceptos de Dios (que es eterno, omnipotente y absoluto) pero estos conceptos no son Dios, porque Dios supera el límite de la razón.

En el segundo momento, Hilario lee la Escritura que le ofrece un doble conocimiento acerca de Dios: el de su ser y el de sus obras -que son precisamente los objetos de los dos caminos metodológicos propuestos por Eunomio-.

Para Hilario la definición de Dios (según Ex 3,14) perfecciona el conocimiento natural acerca de la unidad y la eternidad de Dios. El conocimiento de las obras (Is 40,2 e Is 66,1s. y luego Sab 13,5) perfecciona la noción de omnipotencia.

En la experiencia que presenta como propia, describe Hilario un camino para acercarse a Dios con espíritu piadoso y humilde. El pensamiento analógico está en el centro de esta experiencia espiritual.

Aparece más claramente un último momento de este camino de la analogía. La confesión de fe desemboca en una confesión de vida y se vuelve eclesial.

5. El punto de partida de la Reflexión trinitaria de Hilario y de EuNOMIO (DE TRINITATE II 1-5)

Hilario desarrolla la teología trinitaria en el libro II del De Trinitate, correspondiendo al primer método teológico según Eunomio.

Ambos autores presentan una estructura semejante. Ambos parten de una confesión de fe, pero, mientras que Hilario la construye a partir de Mt 28,19-20, Eunomio lo hará a partir de 1Cor 8,6.

Hilario afirma rotundamente que la confesión de la fe trinitaria en la fórmula bautismal de Mt 28 ofrece un conocimiento suficiente para quien cree. Pues:

Todo es completo como que viene del completo, y perfecto puesto que viene del perfecto $[\ldots]^{27}$.

Analizando el texto, subraya los elementos que contiene:

27 "Plena sunt omnia ut a pleno, et a perfecto perfecta [...]." Hilario, De Trinitate, II 1,71 . 
[...] pues este pasaje contiene la significación exacta de las palabras (verborum significationem), la realidad de las cosas (efficientiam rerum), el orden de las funciones (negotiorum ordinem) y la comprensión de la naturaleza (naturae intelligentiam) ${ }^{28}$.

Es evidente que Hilario tiene en mente la teología neoarriana como la hemos visto en Eunomio.

Le sigue una síntesis de la doctrina trinitaria ${ }^{29}$ que desarrollará en el resto de la obra.

Y sin embargo -a pesar de que el texto de la Escritura es completo y perfecto-, a causa de los herejes, debe añadir una explicación:

Pero por los errores de los herejes y blasfemos nos vemos obligados a hacer lo que no es lícito [...] a ampliar nuestro humilde lenguaje hasta hablar de las cosas que son inexpresables; a causa del error ajeno, nos encontramos forzados a exponernos al error ${ }^{30}$.

Y más adelante lo repite:

La fórmula de fe es clara; pero por lo que respecta a todos los herejes, el sentido de las palabras es incierto ${ }^{31}$.

Las mismas consideraciones encontramos en la Apología de Eunomio. Afirma que la confesión de fe que presenta contiene todo lo que un cristiano debe creer. Pero inmediatamente, afirma que es necesario desarrollarla para defenderla de las interpretaciones equivocadas:

28 «Nam et verborum significationem et efficientiam rerum, et negotiorum ordinem, et naturae intelligentiam comprehendunt.» Hilario, De Trinitate, II 1, 71.

29 Hilario, De Trinitate, II 1, 71-72: "Mandó bautizar en el nombre del Padre y del Hijo y del Espíritu santo, es decir, en la confesión del autor, del unigénito y del don. Uno solo es el Autor de todas las cosas, pues uno solo es Dios Padre, del que todo procede. Y uno solo el Señor nuestro Jesucristo, por medio del cual todo fue hecho. Y un solo Espíritu, don en todos. Todas las cosas están ordenadas según sus atributos y su actuación: una sola potencia de la que todo procede; un solo engendrado por medio del cual todo fue hecho; un solo don en el que tenemos la perfecta esperanza. Nada se echará en falta en una perfección tan grande, en la cual, en el Padre, el Hijo y el Espíritu santo, se hallan la inmensidad en el eterno, la revelación en la imagen, el gozo en el don."

30 "Sed compellimur haereticorum et blasphemantium vitiis, illicita agere [...] cogimur sermonis nostri humilitatem ad ea quae inenarrabilis sunt extendere, et in vitium vitio coartamur alieno." Hilario, De Trinitate, II 2, 72-73.

31 "Forma fidei certa est: sed quantum ad haereticis omnis sensus incertus est." Hilario, De Trinitate, II 5, 76. 
Pero esta profesión no es suficiente para la confirmación de la verdad cuando, con mala intención o por alguna otra perversidad del juicio, se proponen deformar o corromper su sentido... ni es suficiente para la resolución de las acusaciones que nos fueron dirigidas ${ }^{32}$.

Luego de estas notas ambos autores comenzarán a desarrollar la teología trinitaria con una estructura simple, según el orden de las personas.

\section{CONCLUSIÓN}

El resultado de este estudio nos ha llevado a aclarar tres puntos acerca de los tres primeros libros del De Trinitate de Hilario:

(1) En primer lugar, la presencia de la teología neoarriana en esta parte de la obra.

(2) De aquí será necesario revisar la fecha de composición de estos tres libros, pues no es posible que Hilario conociera tan profundamente la teología de la secta anomea al comienzo de su exilio.

(3) Por último, hemos visto que las notas autobiográficas del libro I, si bien no tienen un valor histórico, tal como opinan Simonetti y Canévet, sí tienen una intención teológica y polémica que se descubre en la consideración de los tres libros como una unidad y en el contexto de la refutación de la teología anomea.

32 Eunomio, Apología, 6, 15. 
